\title{
The Role of Long Non- Coding RNAs in the Pathogenesis of Multiple Sclerosis
}

\section{Emad Kioumarsi ${ }^{1}$, Leila Kohan ${ }^{1}$, Farshid Noorbakhsh ${ }^{2 *}$, Sadegh Shirian ${ }^{5,6}$, Ali Gorji ${ }^{3,4}$, Mohammad Shahverdi}

'Department of Biology, Arsanjan Branch, Islamic Azad University, Arsnajan, Iran

${ }^{2}$ Department of Immunology, Tehran University of Medical Sciences, Tehran, Iran

${ }^{3}$ Epilepsy Research Center, Department of Neurosurgery, Westfälische Wilhelms-Universitat Münster, Münster, Germany

${ }^{4}$ Shefa Neuroscience Research Center, Khatam Alanbia Hospital, Tehran, Iran

${ }^{5}$ Department of Pathology, School of Veterinary Medicine, Shahrekord University, Shahrekord, Iran

${ }^{6}$ Shiraz Molecular Pathology Research Center, Dr Daneshbod Pathology Lab, Shiraz, Iran

\section{Article Info:}

\section{ABSTRACT}

Introduction: Multiple sclerosis (MS) is a chronic inflammatory neurological disease with unknown etiology that causes demyelination and axonal damage through the activation of the immune system and entry of leukocytes into the CNS. Although various genetic and environmental factors have been proposed for the initiation and progression of MS, exact mechanisms that cause this disorder are not known. In recent years, the role of non- coding RNAs (ncRNA) has been extensively investigated in the pathogenesis of various diseases, including CNS disorders. A subgroup of ncRNAs that have a length of more than 200 nucleotides is called long non- coding RNAs or lncRNAs. The Discovery of lncRNAs and their role in gene expression regulation has opened a new area of research in cell biology as well as in studies that focus on disease mechanisms. Several investigations have suggested that lncRNAs regulate immune cells and immunological processes, including those affecting CNS disorders. This review article is focused on the role of lncRNA in the pathogenesis of MS. Conclusion: IncRNAs regulate gene expression and cellular functions, including proliferation, differentiation, and apoptosis. lncRNAs are important players in human health and disease. They are also involved in the activation and functioning of innate and adaptive immune cells and hence in immune- related disorders. Understanding the type and function of lncRNAs involved in the pathogenesis of MS can promote the diagnosis and treatment of the disease.

*Corresponding Author: Farshid Noorbakhsh

Email: f-noorbakhsh@sina.tums.ac.ir 


\title{
نقش RNA هاى غير كد كنندهُ بلند در بيمارىزايى بيمارى مالتييل اسكلروزيس
}

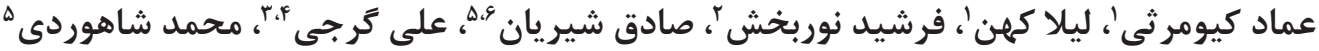

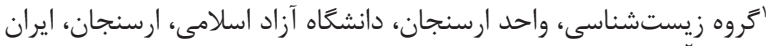

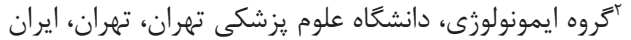

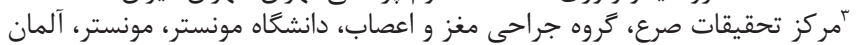

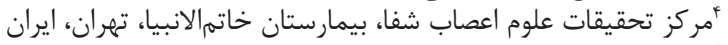

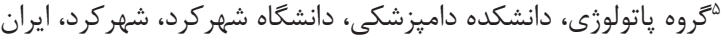

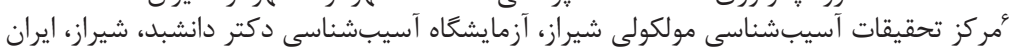

وازههاى كليدى:

1 - مالتيِل اسكلروزيس

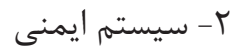

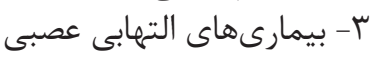

هNA - أ هاى ترجمه نشده

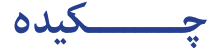

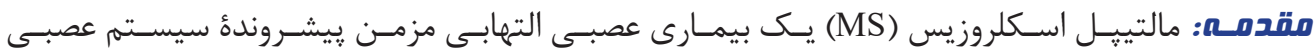

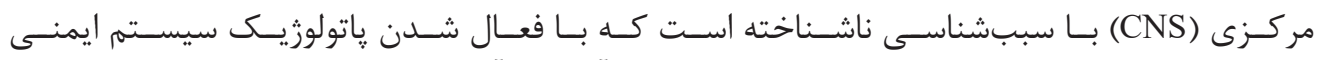

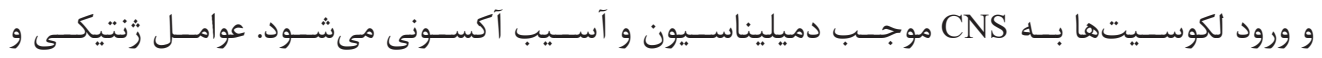

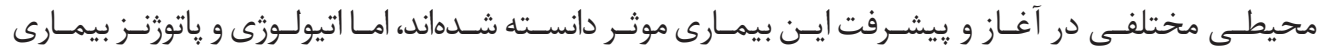

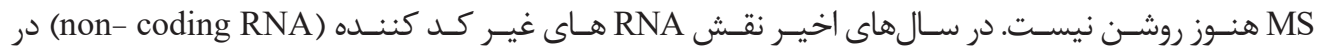

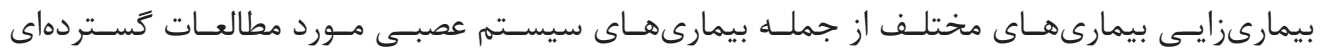

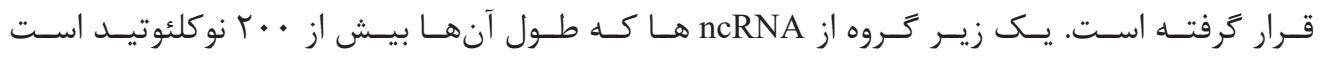

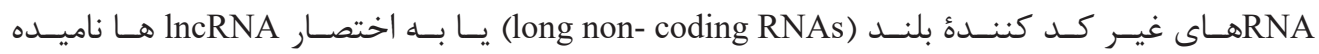

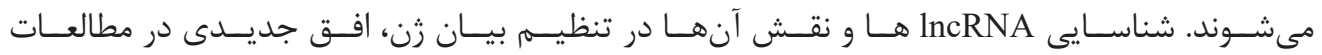

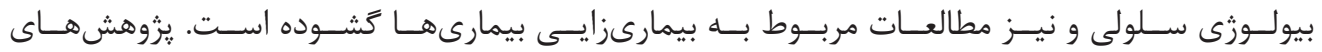

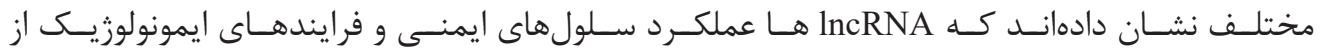

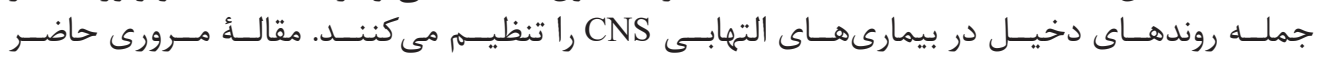

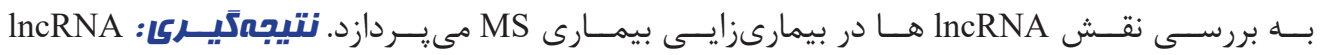

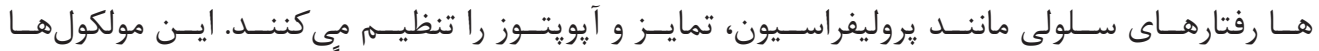

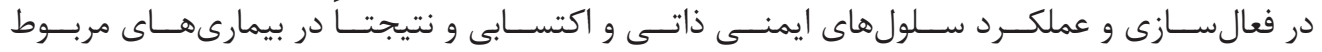

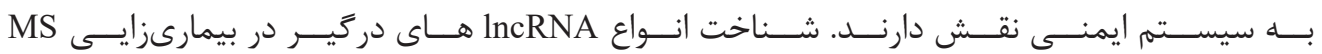

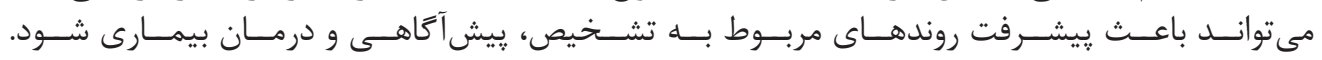

$$
\text { *ونسينده مسئول: فرشيد نوربخش }
$$




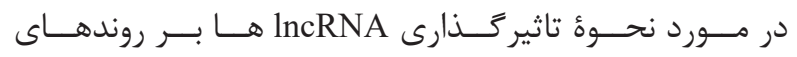

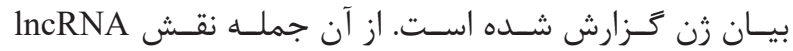

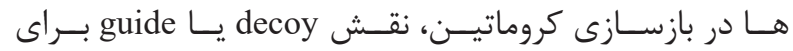

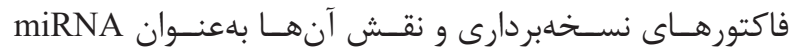
دادة sponge

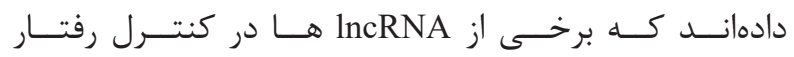

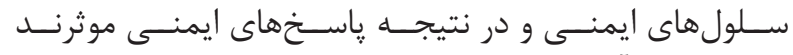

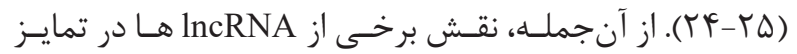

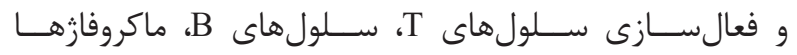

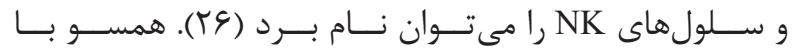

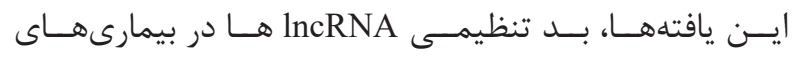

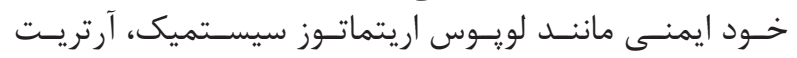

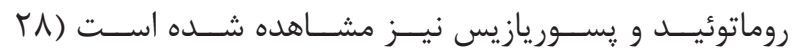

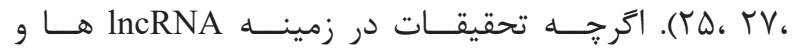

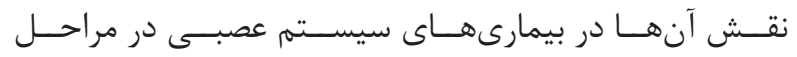

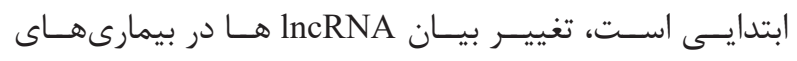
CNS

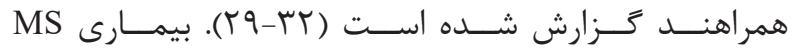

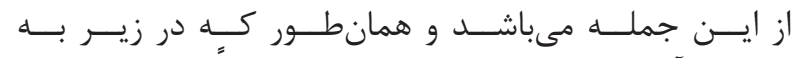

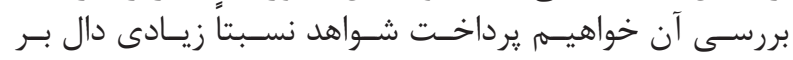

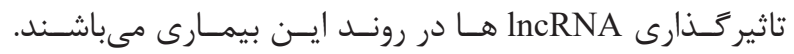

\section{MS ها در بيمارى IncRNA}

TUG1

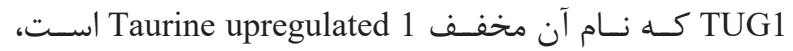

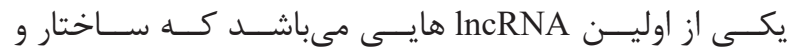

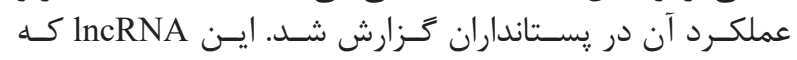

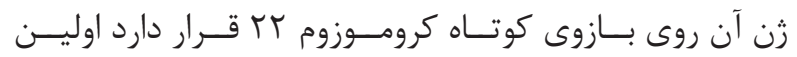

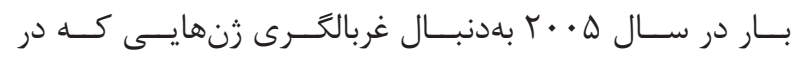

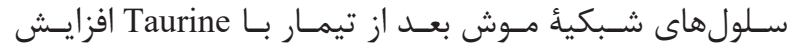

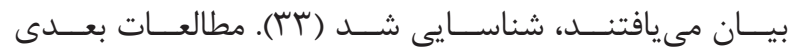

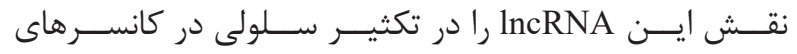

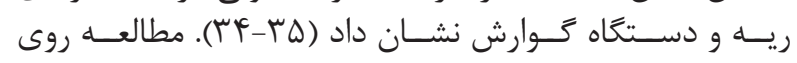

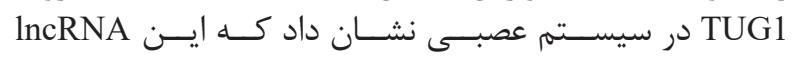

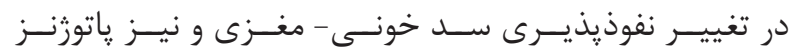

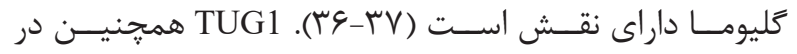

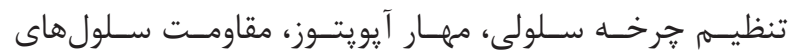

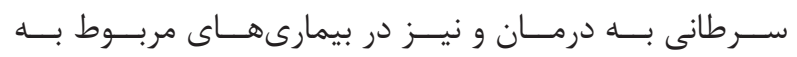

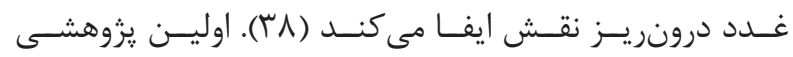

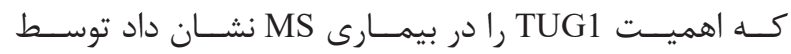
Santoro

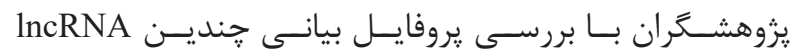

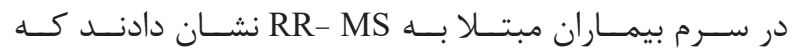

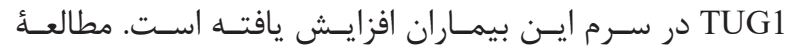

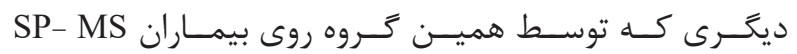

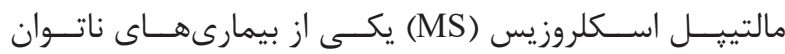

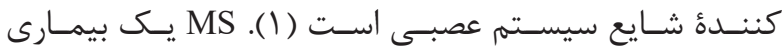

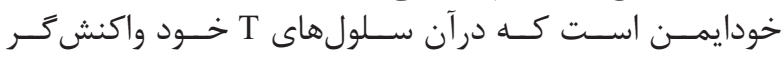

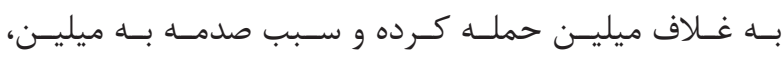

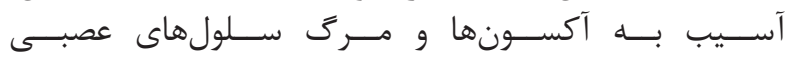

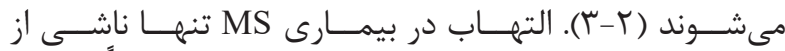

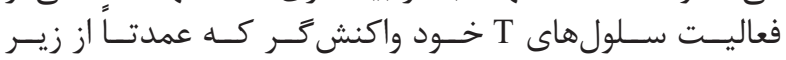

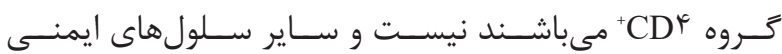

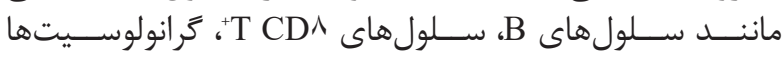

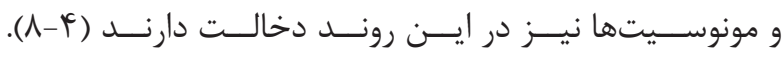

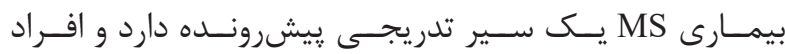

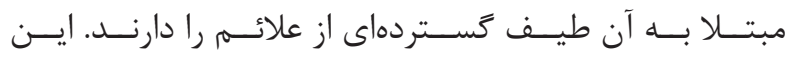

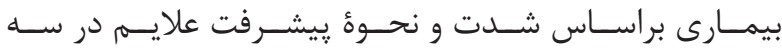

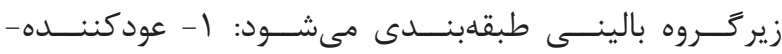

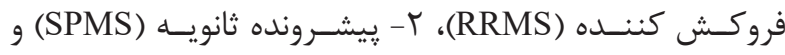

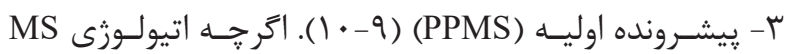

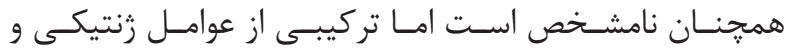

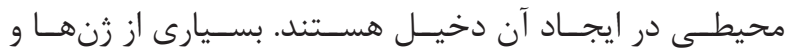

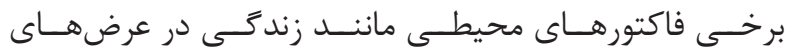

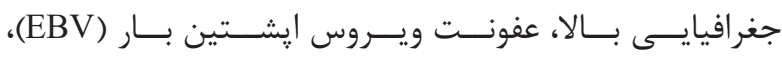

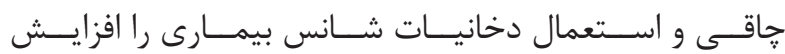

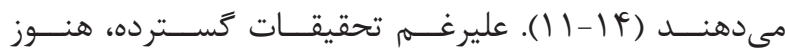

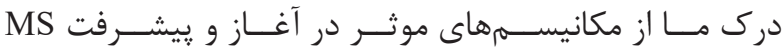

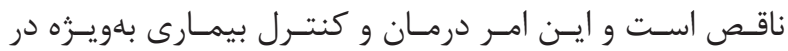

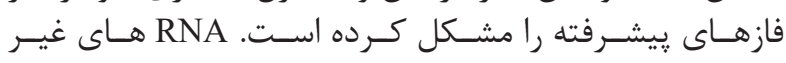

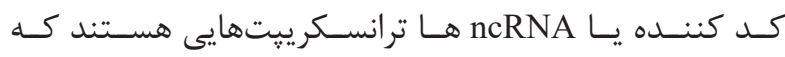

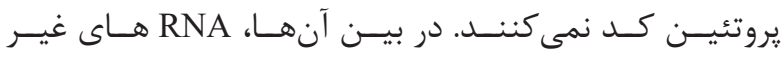

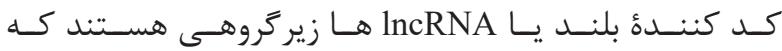

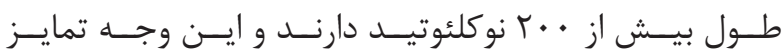

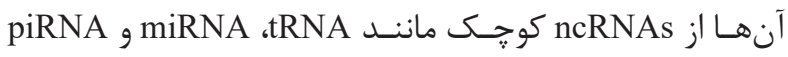

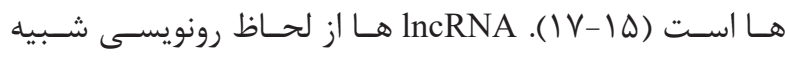

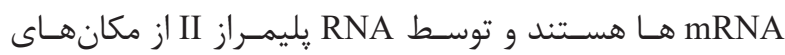

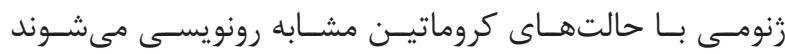

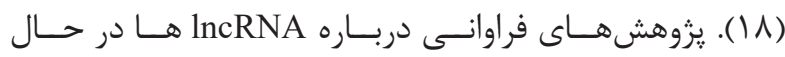

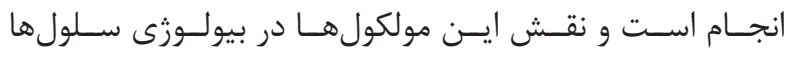

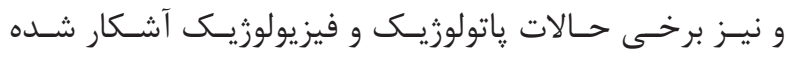

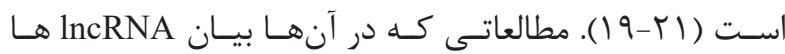

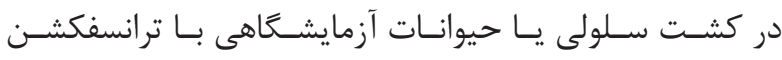

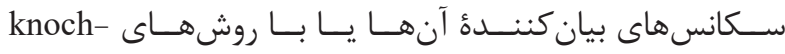

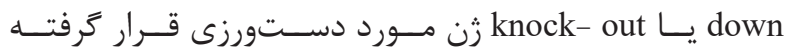

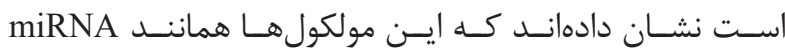

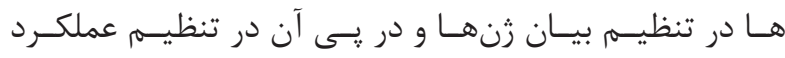

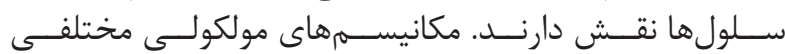




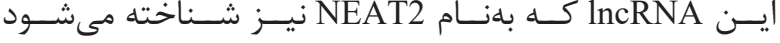

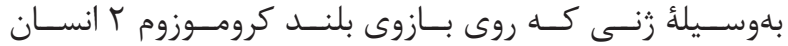

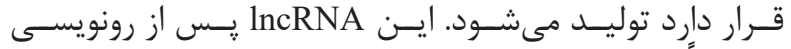

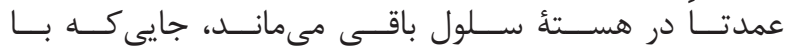

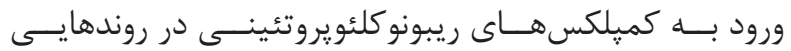

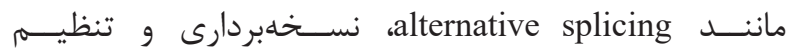

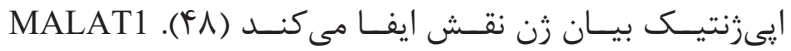

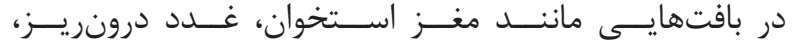

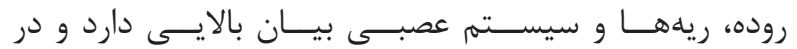

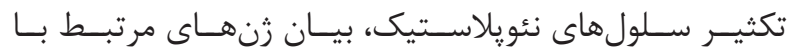

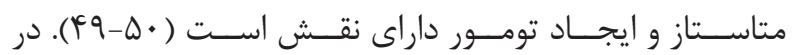

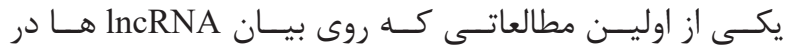

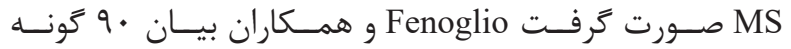
مC IncRNA

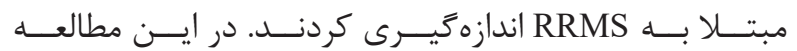

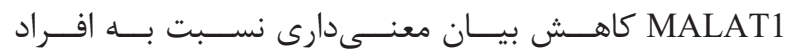

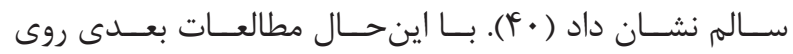

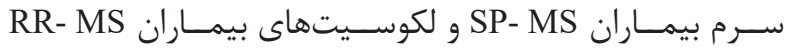

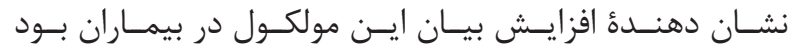

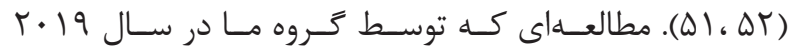

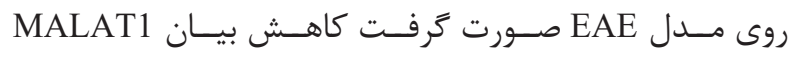

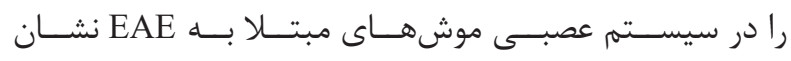

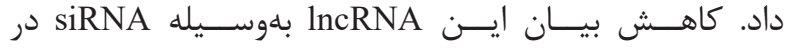

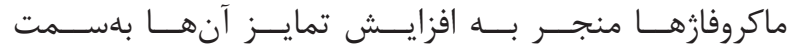

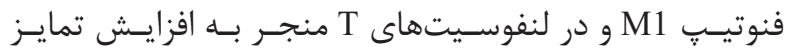

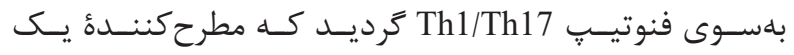

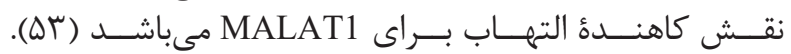

NEAT1

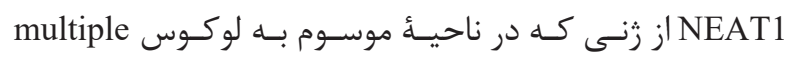
endocrie neoplasia

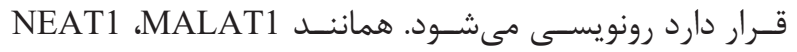

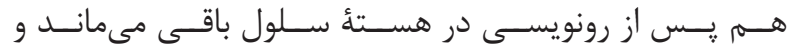

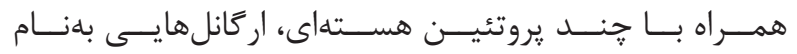

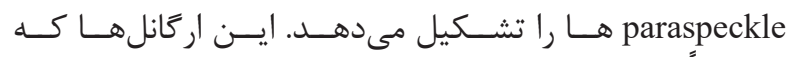

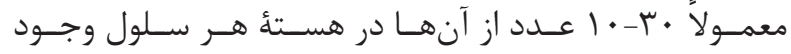

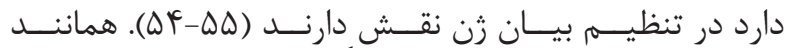

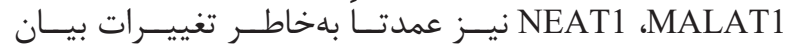

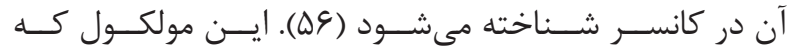

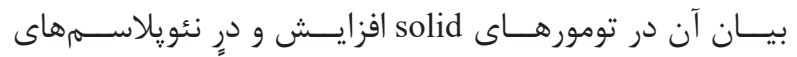

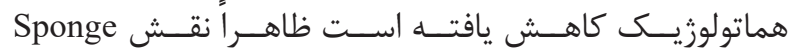

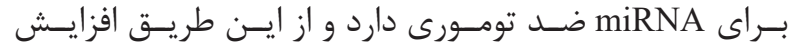

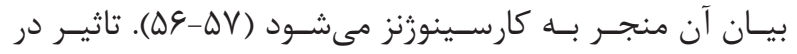

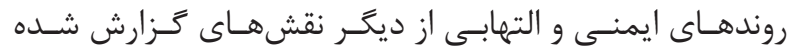

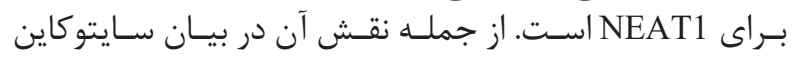

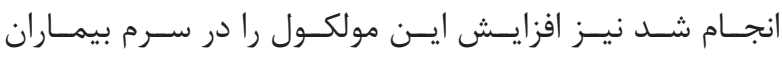

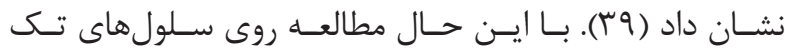

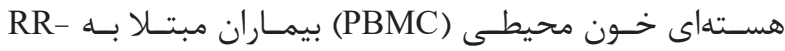

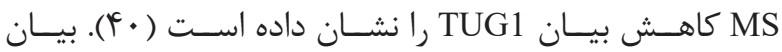

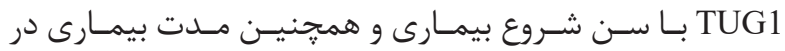

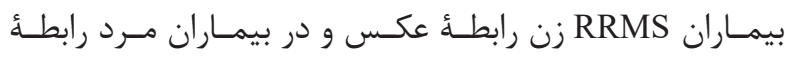

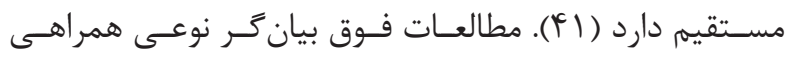
(association)

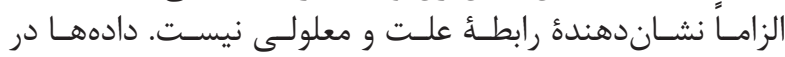

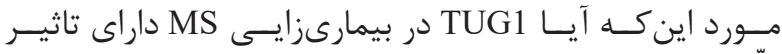

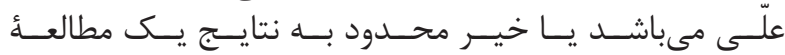

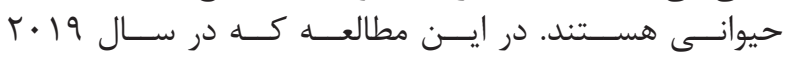

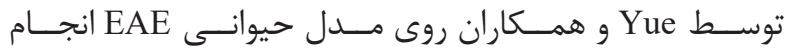

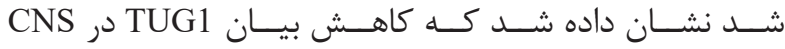

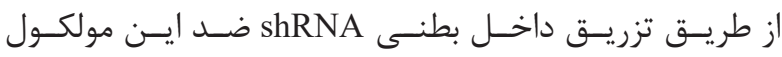

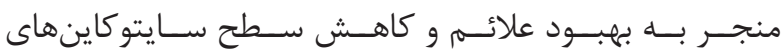

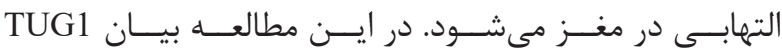

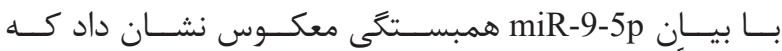

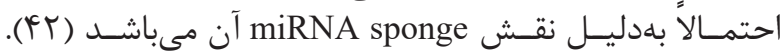

\section{LRRC75A-AS1}

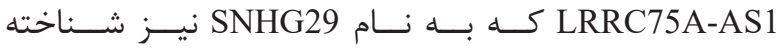

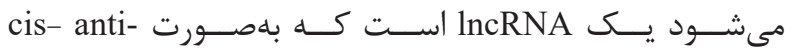

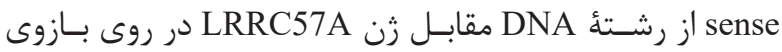

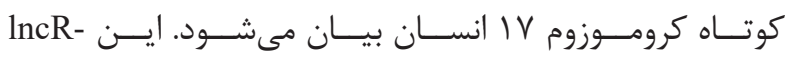

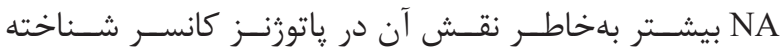

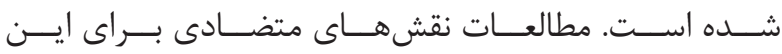

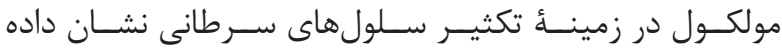

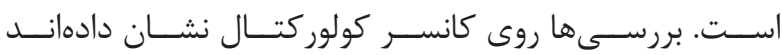

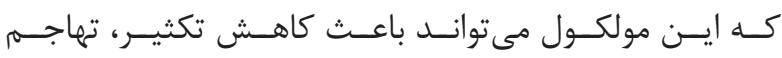

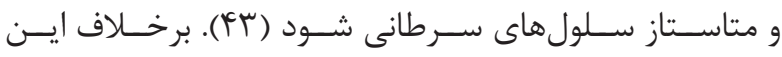

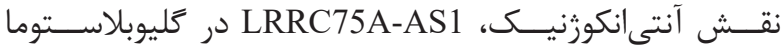

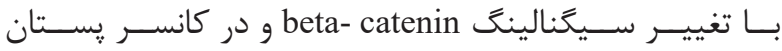
miRNA sponge triple negative

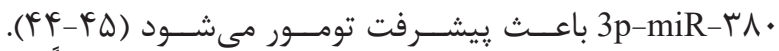

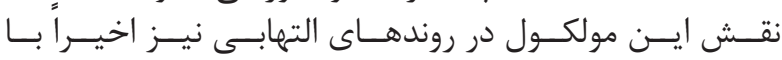

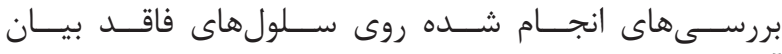

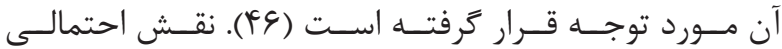

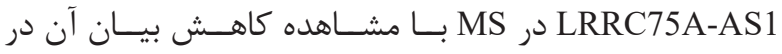

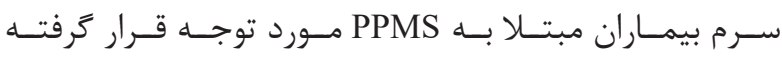

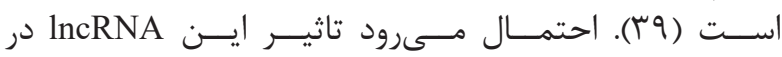

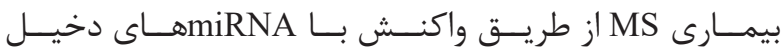

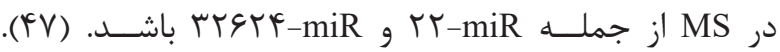

MALAT1 


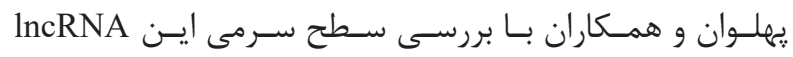

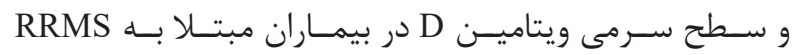

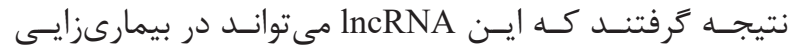

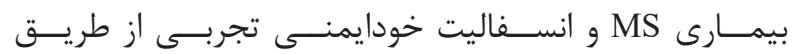

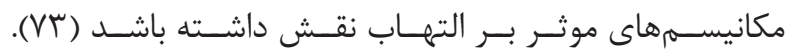

IncDDIT4

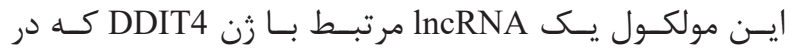

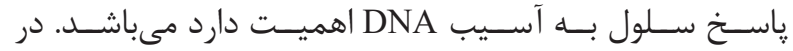

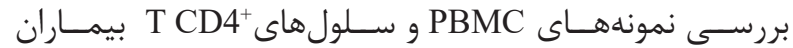

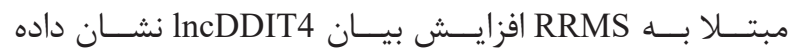

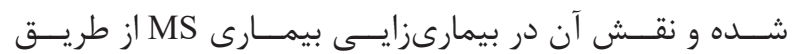

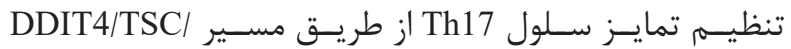

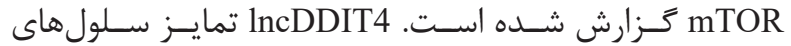
Th17 بـا هـدف قـرار دادن DDIT4 را تنظيـم مى كنـد (VF).

\section{MAFTRR}

مولكــول MAFTRR كـــه بــهـ نــام LincMAF-4 نيـز

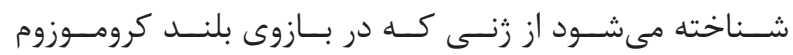

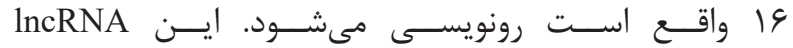

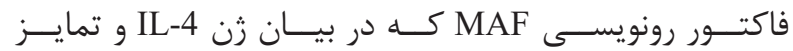

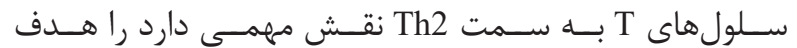

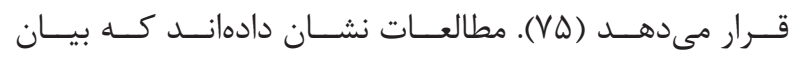

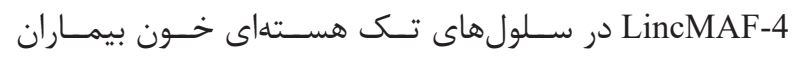

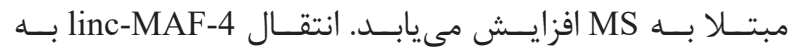

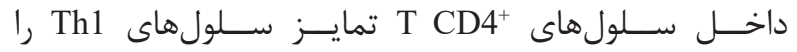

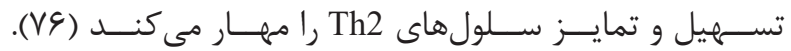

\section{MEG3a}

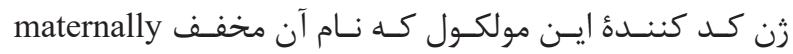
مى expressed gene 3

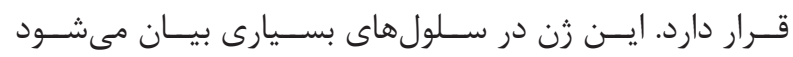

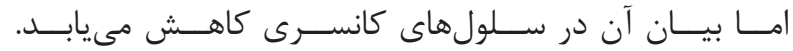

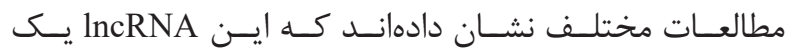
tumor supressor

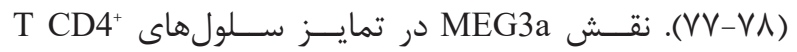

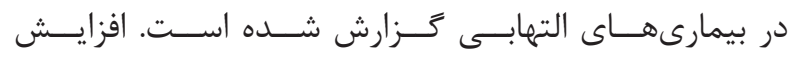

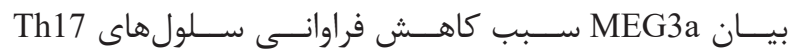

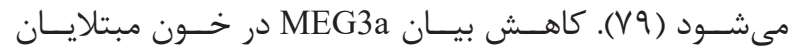

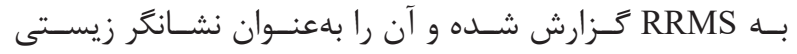

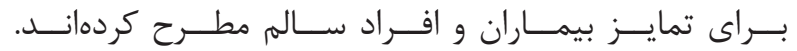

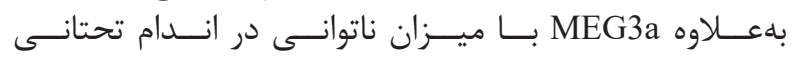

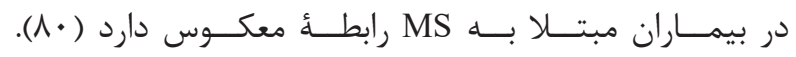

PANDAR

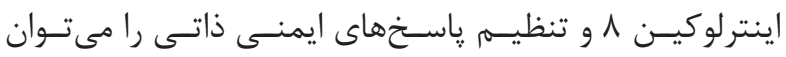

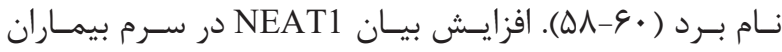
RRMS

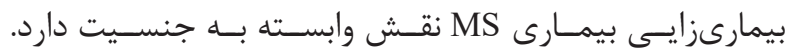

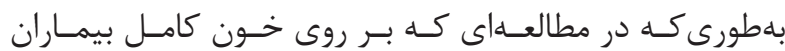

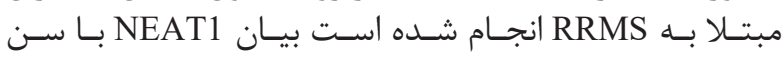

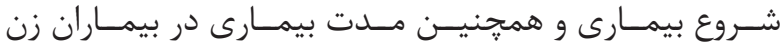

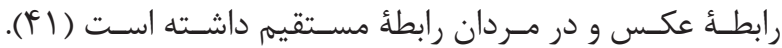

IFNG-AS1

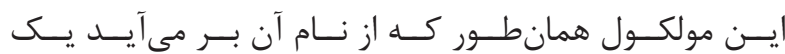

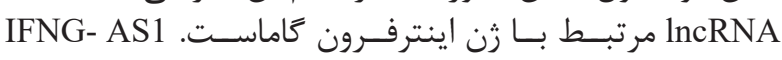

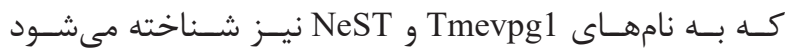

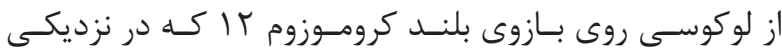

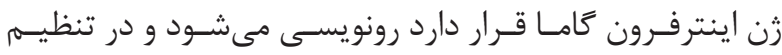

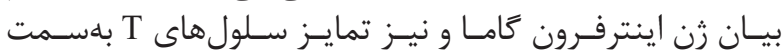

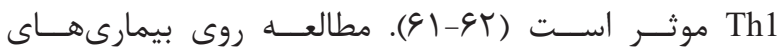

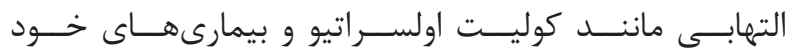

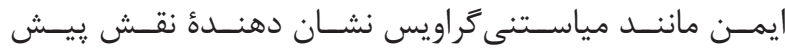

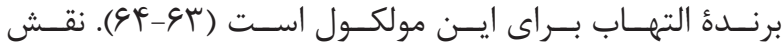

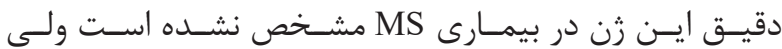

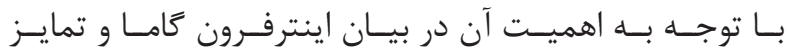

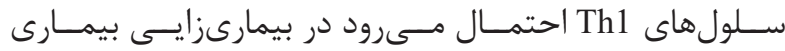

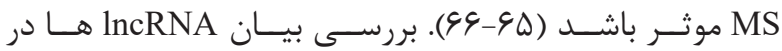

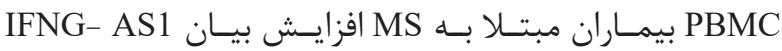

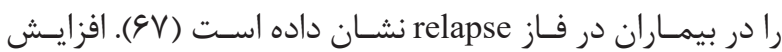

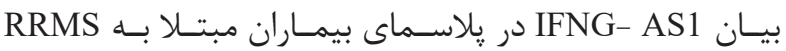

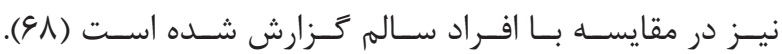

\section{HOTAIR}

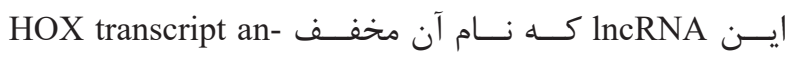
tisense RNA

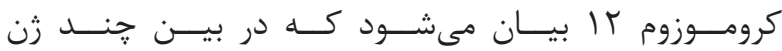

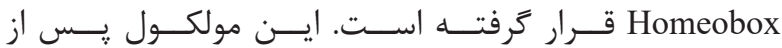

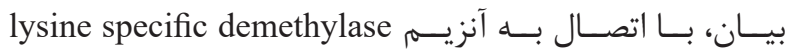

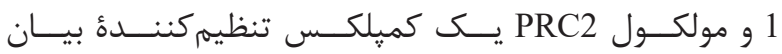

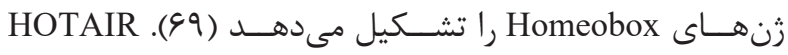

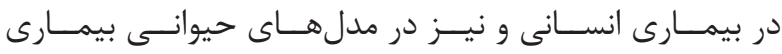

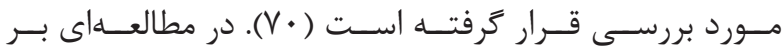

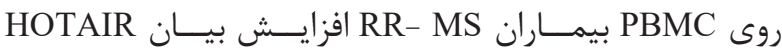

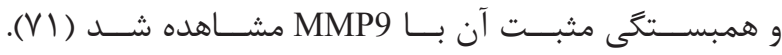

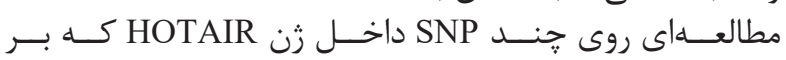

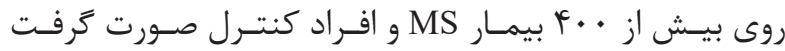

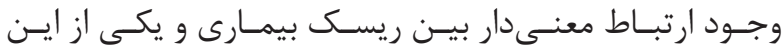

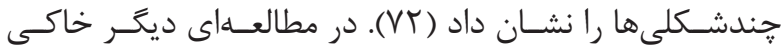




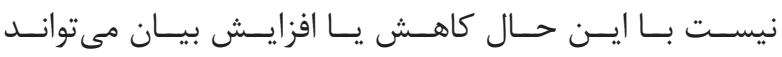

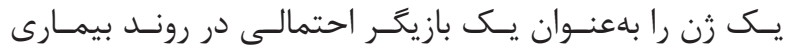

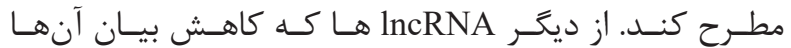

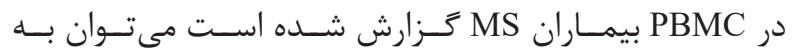
GOMAFU، SOX2OT، XIST، ANRIL، NRON، MEG9 ‘PVT1 ،LincR-Epas1-3، AS ،BACE-1AS ،HULC ،

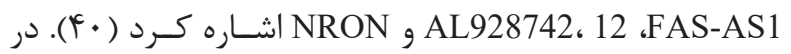

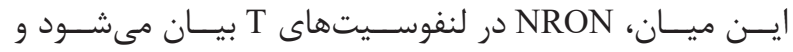

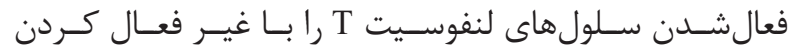

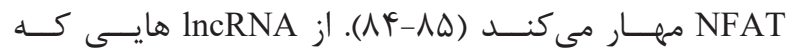

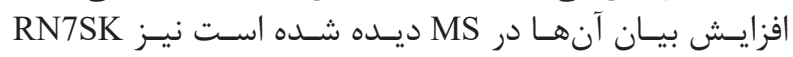
RNA

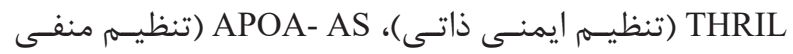

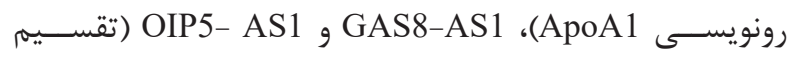

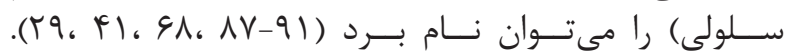
نتيجه گيبرى

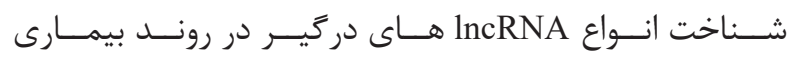

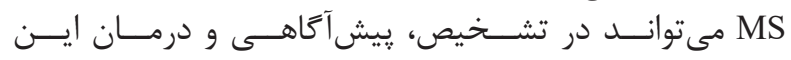

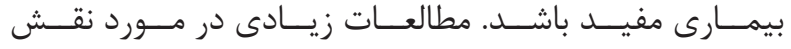

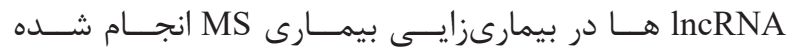

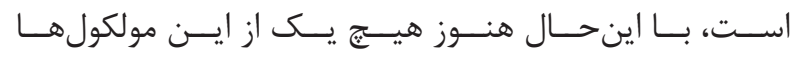

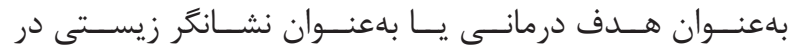

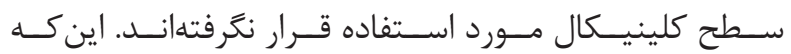

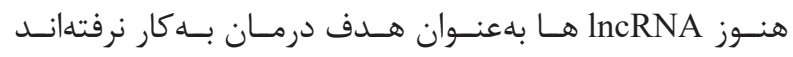

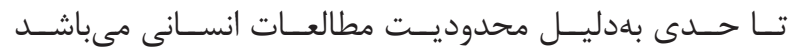

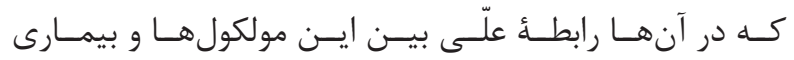

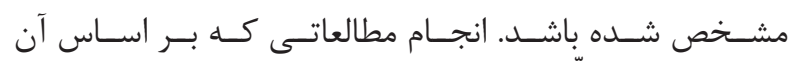

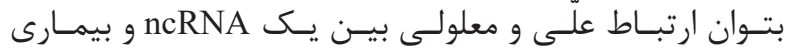

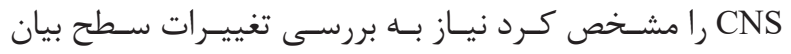

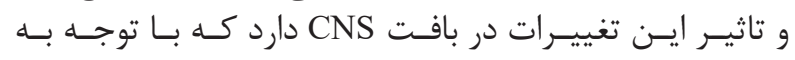

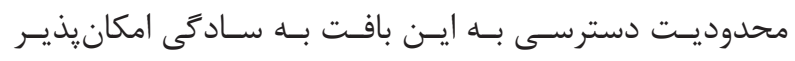

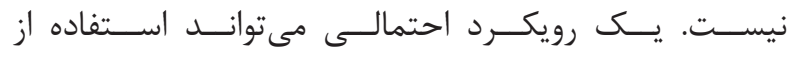

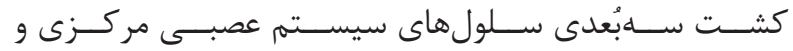

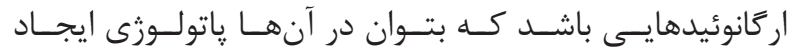

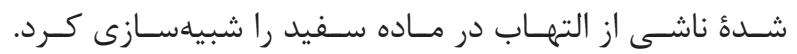

1. Kobelt G, Thompson A, Berg J, Gannedahl M, Eriksson J, Group MS, et al. New insights into the burden and costs of multiple sclerosis in Europe. Multiple Sclerosis Journal. 2017;1123-36 :(8)23 .

2. Hemmer B, Archelos JJ, Hartung HP. New concepts in the immunopathogenesis of multiple sclerosis. Nat Rev Neurosci. 2002;3(4): 291-301.

3. Sospedra M, Martin R. Immunology of multiple sclerosis. Annu Rev Immunol. 2005;683-747 :23 .

4. Mimpen M, Smolders J, Hupperts R, Dam-
ايسن مولكـول كــه نـام آن مخفـف P21 associated ncRNA

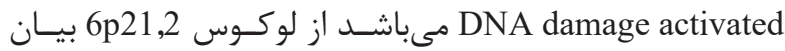

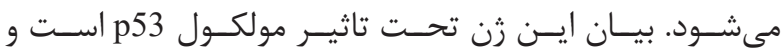

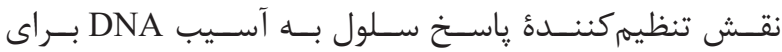

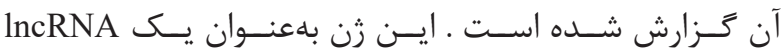

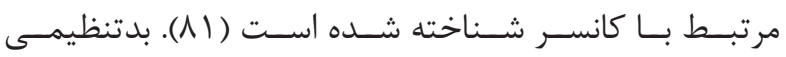

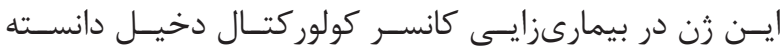

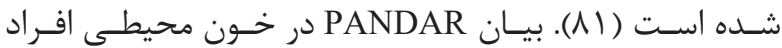

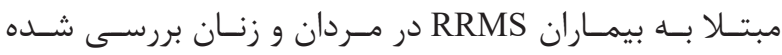

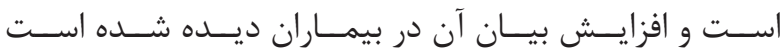

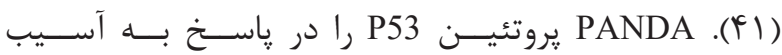

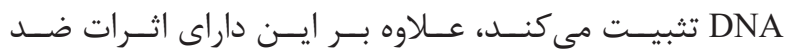

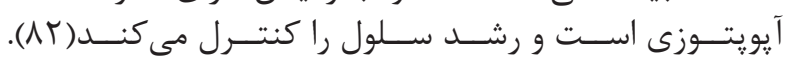

Inc-DC

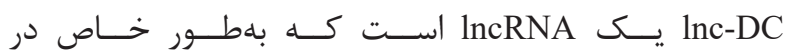

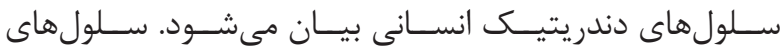

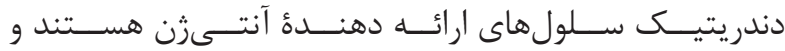

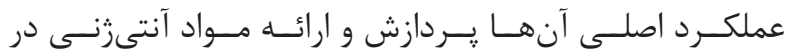

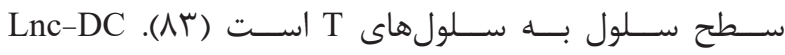

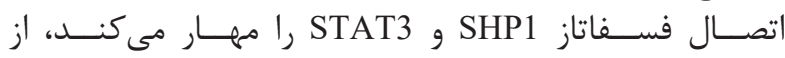

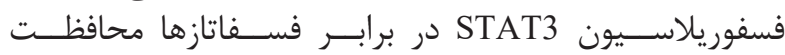

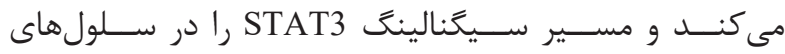

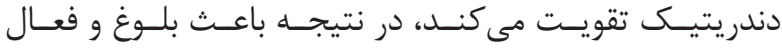

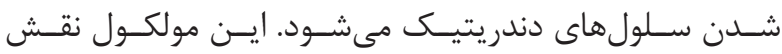

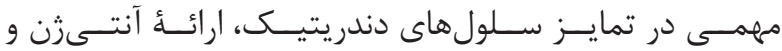

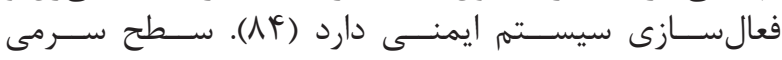

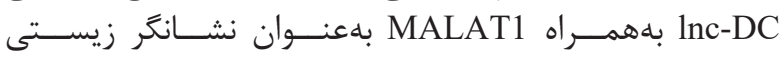

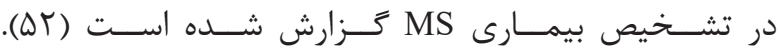

ساير IncRNA سا

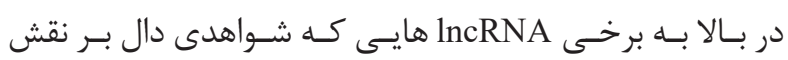

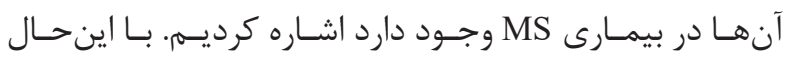

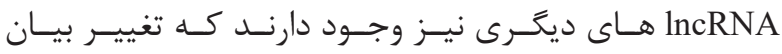

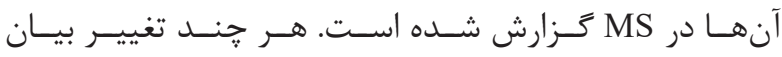

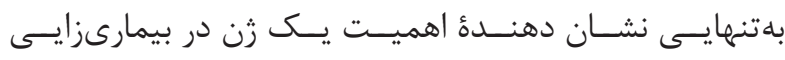

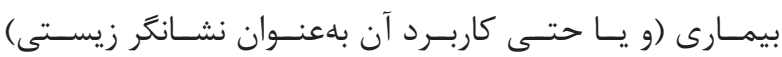

منابع oiseaux J. Natural killer cells in multiple sclerosis: A review. Immunol Lett. 2020; 222: 1-11.

5. Mockus TE, Munie A, Atkinson JR, Segal BM. Encephalitogenic and Regulatory CD8 T Cells in Multiple Sclerosis and Its Animal Models. J Immunol. 2021; 206(1): 3-10.

6. Racke MK. The role of $B$ cells in multiple sclerosis: rationale for B-cell-targeted therapies. Curr Opin Neurol. 2008; 21 Suppl 1: S9-S18.

7. Salou M, Nicol B, Garcia A, Laplaud DA. 
Involvement of $\mathrm{CD} 8(+) \mathrm{T}$ Cells in Multiple Sclerosis. Front Immunol. 2015; 6: 604.

8. Woodberry T, Bouffler SE, Wilson AS, Buckland RL, Brustle A. The Emerging Role of Neutrophil Granulocytes in Multiple Sclerosis. J Clin Med. 2018; 7(12).

9. Klineova S, Lublin FD. Clinical Course of Multiple Sclerosis. Cold Spring Harb Perspect Med. 2018; 8(9).

10. Lublin FD, Reingold SC, Cohen JA, Cutter GR, Sorensen PS, Thompson AJ, et al. Defining the clinical course of multiple sclerosis: the 2013 revisions. Neurology. 2014; 83(3): 278-86.

11. Ascherio A. Environmental factors in multiple sclerosis. Expert review of neurotherapeutics. 2013;13 (sup2): 3-9.

12. Belbasis L, Bellou V, Evangelou E, Tzoulaki I. Environmental factors and risk of multiple sclerosis: Findings from meta-analyses and Mendelian randomization studies. Mult Scler. 2020; 26(4): 397-404.

13. Martin R, Sospedra M, Eiermann T, Olsson T. Multiple sclerosis: doubling down on MHC. Trends Genet. 2021; 37(9): 784-97.

14. Behroozi Z, Atefimanesh P, Karimzadeh F. Structural andMetabolicBiomarkers in MultipleSclerosis. TheNeuroscience Journal of Shefaye Khatam. 2018; 6(2): 94-108.

15. Carninci P, Hayashizaki Y. Noncoding RNA transcription beyond annotated genes. Curr Opin Genet Dev. 2007; 17(2): 139-44.

16. Jandura A, Krause HM. The New RNA World: Growing Evidence for Long Noncoding RNA Functionality. Trends Genet. 2017; 33(10): 665-76.

17. Wilusz JE, Sunwoo H, Spector DL. Long noncoding RNAs: functional surprises from the RNA world. Genes \& development. 2009; 23(13): 1494-504.

18. Quinn JJ, Chang HY. Unique features of long non-coding RNA biogenesis and function. Nature Reviews Genetics. 2016; 17(1): 47.

19. Guo J, Liu Z, Gong R. Long noncoding RNA: an emerging player in diabetes and diabetic kidney disease. Clin Sci (Lond). 2019; 133(12): 1321-39.

20. Salamon I, Saccani Jotti G, Condorelli G. The long noncoding RNA landscape in cardiovascular disease: a brief update. Curr Opin Cardiol. 2018; 33(3): 282-9.

21. Schmitz SU, Grote P, Herrmann BG. Mechanisms of long noncoding RNA function in development and disease. Cell Mol Life Sci. 2016; 73(13): 2491-509.

22. Wang KC, Chang HY. Molecular mechanisms of long noncoding RNAs. Mol Cell. 2011; 43(6): 904-14.

23. Bartonicek N, Maag JL, Dinger ME. Long noncoding RNAs in cancer: mechanisms of action and technological advancements. Mol Cancer. 2016; 15(1): 43.

24. Satpathy AT, ChangHY.LongnoncodingRNAinhematopoiesis and immunity. Immunity. 2015; 42(5): 792-804.

25. Sigdel KR, Cheng A, Wang Y, Duan L, Zhang Y. The Emerging Functions of Long Noncoding RNA in Immune Cells: Autoimmune Diseases. J Immunol Res. 2015; 790-848.

26. Ahmad I, Valverde A, Ahmad F, Naqvi AR. Long Noncoding RNA in Myeloid and Lymphoid Cell Differentiation, Polarization and Function. Cells. 2020; 9(2).

27. Yan J, Song J, Qiao M, Zhao X, Li R, Jiao J, et al. Long noncoding RNA expression profile and functional analysis in psoriasis. Mol Med Rep. 2019; 19(5): 3421-30.

28. Peng H, Ren S, Liu Y, Zhou H, Tang X, Yang J, Tian J, Xu P, Xu H, Wang S. Elevated expression of the long noncoding RNA IFNG-AS1 in the peripheral blood from patients with rheumatoid arthritis. Journal of immunology research. 2020 Jan 30;2020 .

29. Santoro M, Nociti V, Lucchini M, De Fino C, Losavio FA, Mirabella M. Expression profile of long non-coding RNAs in serum of patients with multiple sclerosis. Journal of Molecular Neuroscience. 2016; 59(1): 18-23.

30. Khojasteh MR, Shariat Razavi A, Javadzadeh A, Gorji A, Sahab Negah S. Cell Therapy: A Therapeutic Option for Multiple Sclerosis. Shefaye Khatam. 2018; 6 (3): 52-68.

31. Wang L, Zeng L, Jiang H, Li Z, Liu R. Microarray Profile of Long Noncoding RNA and Messenger RNA Expression in a Model of Alzheimer's Disease. Life (Basel). 2020; 10(5).

32. Zhai K, Liu B, GAO L. Long-Noncoding RNA TUG1 Promotes Parkinson's disease via Modulating MiR-152-3p/PTEN Pathway. Hum Gene Ther. 2020; 31(23-24): 1274-87.

33. Young TL, Matsuda T, Cepko CL. The noncoding RNA taurine upregulated gene 1 is required for differentiation of the murine retina. Curr Biol. 2005; 15(6): 501-12.

34. Zhang EB, Yin DD, Sun M, Kong R, Liu XH, You LH, et al. P53-regulated long non-coding RNA TUG1 affects cell proliferation in human non-small cell lung cancer, partly through epigenetically regulating 


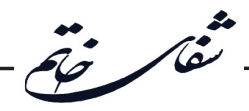

HOXB7 expression. Cell Death Dis. 2014; 5: e1243.

35. Xu Y, Wang J, Qiu M, Xu L, Li M, Jiang F, et al. Upregulation of the long noncoding RNA TUG1 promotes proliferation and migration of esophageal squamous cell carcinoma. Tumour Biol. 2015; 36(3): 1643-51.

36. Cai $\mathrm{H}$, Xue Y, Wang $\mathrm{P}$, Wang Z, Li Z, Hu $\mathrm{Y}$, et al. The long noncoding RNA TUG1 regulates blood-tumor barrier permeability by targeting miR-144. Oncotarget. 2015; 6(23): 19759-79.

37. Li J, An G, Zhang M, Ma Q. Long non-coding RNA TUG1 acts as a miR-26a sponge in human glioma cells. Biochem Biophys Res Commun. 2016; 477(4): 743-8.

38. Guo C, Qi Y, Qu J, Gai L, Shi Y, Yuan C. Pathophysiological Functions of the lncRNA TUG1. Current pharmaceutical design. 2020; 26(6): 688-700.

39. Santoro M, Nociti V, Lucchini M, Loiodice M, Centofanti F, Botta A, et al. A pilot study of lncRNAs expression profile in serum of progressive multiple sclerosis patients. European review for medical and pharmacological sciences. 2020; 24(6): 3267-73.

40. Fenoglio C, Oldoni E, Serpente M, Milena A, Arcaro M, D'Anca M, et al. LncRNAs expression profile in peripheral blood mononuclear cells from multiple sclerosis patients.Journalofneuroimmunology.2018;324:129-35.

41. Dastmalchi R, Ghafouri-Fard S, Omrani MD, Mazdeh M, Sayad A, Taheri M. Dysregulation of long non-coding RNA profile in peripheral blood of multiple sclerosis patients. Multiple sclerosis and related disorders. 2018; 25: 219-26.

42. Yue P, Jing L, Zhao X, Zhu H, Teng J. Down-regulation of taurine-up-regulated gene 1 attenuates inflammation by sponging miR-9-5p via targeting NF-kappaB1/ p50 in multiple sclerosis. Life Sci. 2019; 233:116731 .

43. Chen J, Lan J, Ye Z, Duan S, Hu Y, Zou Y, et al. Long noncoding RNA LRRC75A-AS1 inhibits cell proliferation and migration in colorectal carcinoma. Exp Biol Med (Maywood). 2019; 244(14): 1137-43.

44. Han L, Li Z, Jiang Y, Jiang Z, Tang L. SNHG29 regulates miR-223-3p/CTNND1 axis to promote glioblastoma progression via Wnt/beta-catenin signaling pathway. Cancer Cell Int. 2019; 19: 345.

45. Li S, Wu D, Jia H, Zhang Z. Long non-coding RNA LRRC75A-AS1 facilitates triple negative breast cancer cell proliferation and invasion via functioning as a ceRNA to modulate BAALC. Cell Death Dis. 2020; 11(8): 643.

46. Wang X, Wang $\mathrm{H}$, Zhang R, Li D, Gao MQ.
LRRC75A antisense lncRNA1 knockout attenuates inflammatory responses of bovine mammary epithelial cells. Int J Biol Sci. 2020; 16(2): 251-63.

47. Siegel SR, Mackenzie J, Chaplin G, Jablonski NG, Griffiths L. Circulating microRNAs involved in multiple sclerosis. Molecularbiologyreports.2012;39(5):6219-25.

48. Eißmann M, Gutschner T, Hämmerle M, Günther S, Caudron-Herger M, Groß M, et al. Loss of the abundant nuclear non-coding RNA MALAT1 is compatible with life and development. RNA biology. 2012; 9(8): 1076-87.

49.LiuJ,PengWX,MoYY,LuoD.MALAT1-mediatedtumorigenesis.FrontBiosci(LandmarkEd).2017;22:66-80.

50. Bernard D, Prasanth KV, Tripathi V, Colasse S, Nakamura T, Xuan Z, et al. A long nuclear-retained non-coding RNA regulates synaptogenesis by modulating gene expression. The EMBO journal. 2010; 29(18): 3082-93.

51. Cardamone G, Paraboschi EM, Solda G, Cantoni C, Supino D, Piccio L, et al. Not only cancer: the long non-coding RNA MALAT1 affects the repertoire of alternatively spliced transcripts and circular RNAs in multiple sclerosis. Hum Mol Genet. 2019; 28(9): 1414-28.

52. Shaker OG, Mahmoud RH, Abdelaleem OO, Ibrahem EG, Mohamed AA, Zaki OM, et al. LncRNAs, MALAT1 and lnc-DC as potential biomarkers for multiple sclerosis diagnosis. Bioscience reports. 2019; 39(1).

53. Masoumi F, Ghorbani S, Talebi F, Branton WG, Rajaei S, Power C, et al. Malat1 long noncoding RNA regulates inflammation and leukocyte differentiation in experimental autoimmune encephalomyelitis. J Neuroimmunol. 2019; 328: 50-9.

54. West JA, Mito M, Kurosaka S, Takumi T, Tanegashima C, Chujo T, et al. Structural, super-resolution microscopy analysis of paraspeckle nuclear body organization. J Cell Biol. 2016; 214(7): 817-30.

55. Wang Z, Li K, Huang W. Long non-coding RNA NEAT1-centric gene regulation. Cell Mol Life Sci. 2020; 77(19): 3769-79.

56. Yu X, Li Z, Zheng $\mathrm{H}$, Chan MT, Wu WK. NEAT1: A novel cancer-related long non-coding RNA. Cell Prolif. 2017; 50(2).

57. Klec C, Prinz F, Pichler M. Involvement of the long noncoding RNA NEAT1 in carcinogenesis. Mol Oncol. 2019; 13(1): 46-60.

58. Imamura K, Imamachi N, Akizuki G, Kumakura M, Kawaguchi A, Nagata $\mathrm{K}$, et al. Long noncoding RNA NEAT1-dependent SFPQ relocation from promoter re- 
gion to paraspeckle mediates IL8 expression upon immune stimuli. Molecular cell. 2014; 53(3): 393-406.

59. Ma H, Han P, Ye W, Chen H, Zheng X, Cheng L, et al. The Long Noncoding RNA NEAT1 Exerts Antihantaviral Effects by Acting as Positive Feedback for RIG-I Signaling. J Virol. 2017; 91(9).

60. Morchikh M, Cribier A, Raffel R, Amraoui S, Cau J, Severac D, et al. HEXIM1 and NEAT1 Long Non-coding RNA Form a Multi-subunit Complex that Regulates DNA-Mediated Innate Immune Response. Mol Cell. 2017; 67(3): 387-99 e5.

61. Peng H, Liu Y, Tian J, Ma J, Tang X, Rui K, et al. The Long Noncoding RNA IFNG-AS1 Promotes T Helper Type 1 Cells Response in Patients with Hashimoto’s Thyroiditis. Sci Rep. 2015;202-177:5 .

62. Collier SP, Henderson MA, Tossberg JT, Aune TM. Regulation of the Th1 genomic locus from Ifng through Tmevpg1 by T-bet. J Immunol. 2014; 193(8):3959-65.

63. Padua D, Mahurkar-Joshi S, Law IK, Polytarchou C, Vu JP, Pisegna JR, et al. A long noncoding RNA signature for ulcerative colitis identifies IFNG-AS1 as an enhancer of inflammation. Am J Physiol Gastrointest Liver Physiol. 2016; 311(3): G446-57.

64.LuoM,LiuX,MengH,XuL,LiY,LiZ, etal.IFNA-AS1 regulates $\mathrm{CD} 4(+) \mathrm{T}$ cell activation in myasthenia gravis though HLA-DRB1. Clin Immunol. 2017; 183: 121-31.

65. Collier SP, Collins PL, Williams CL, Boothby MR, Aune TM. Cutting edge: influence of Tmevpg1, a long intergenic noncoding RNA, on the expression ofIfng by Th1 cells. The Journal of Immunology. 2012; 189(5): 2084-8.

66. Collier SP, Henderson MA, Tossberg JT, Aune TM. Regulation of the Th1 genomic locus from Ifng through Tmevpg1 by T-bet. The Journal of Immunology. 2014; 193(8): 3959-65.

67. Hosseini A, Teimuri S, Ehsani M, Rasa SMM, EtemadifarM, Nasr Esfahani MH, et al.LncRNAs associated with multiple sclerosis expressed in the Th1 cell lineage. Journal of cellular physiology. 2019; 234(12): 22153-62.

68. Ghaiad HR, Elmazny AN, Nooh MM, El-Sawalhi MM, Shaheen AA. Long noncoding RNAs APOA1AS, IFNG-AS1, RMRP and their related biomolecules in Egyptian patients with relapsing-remitting multiple sclerosis: Relation to disease activity and patient disability. Journal of advanced research. 2020; 21: 141-50.

69. Tsai MC, Manor O, Wan Y, Mosammaparast $\mathrm{N}$, Wang JK, Lan $\mathrm{F}$, et al. Long noncoding RNA as modular scaffold of histone modification complexes. Science. 2010; 329(5992): 689-93.
70. Pahlevan Kakhki M, Nikravesh A, Shirvani Farsani Z, Sahraian MA, Behmanesh M. HOTAIR but not ANRIL long non-coding RNA contributes to the pathogenesis of multiple sclerosis. Immunology. 2018; 153(4): 479-87.

71. Soltanmoradi S, Tavakolpour V, Moghadasi AN, Kouhkan F. Expression analysis of NF-kappaB-associated long noncoding RNAs in peripheral blood mononuclear cells from relapsing-remitting multiple sclerosis patients. J Neuroimmunol. 2021; 356: 577-602.

72. Taheri M, Noroozi R, Sadeghpour S, Omrani MD, Ghafouri-Fard S. The rs4759314 SNP within Hotair lncRNA is associated with risk of multiple sclerosis. Mult Scler Relat Disord. 2020; 40: 1019-86.

73. Riege K, Hölzer M, Klassert TE, Barth E, Bräuer J, Collatz M, et al. Massive effect on LncRNAs in human monocytes during fungal and bacterial infections and in response to vitamins A and D. Scientific reports. 2017; 7(1): 1-13.

74. Zhang F, Liu G, Li D, Wei C, Hao J. DDIT4 and associated lncDDIT4 modulate Th17 differentiation through the DDIT4/TSC/mTOR pathway. The Journal of Immunology. 2018; 200(5): 1618-26.

75. Ho IC, Lo D, Glimcher LH. C-maf promotes T helper cell type 2 (Th2) and attenuates Th1 differentiation by both interleukin 4-dependent and -independent mechanisms. J Exp Med. 1998; 188(10): 1859-66.

76. Zhang F, Liu G, Wei C, Gao C, Hao J. Linc-MAF-4 regulates $\mathrm{Th} 1 / \mathrm{Th} 2$ differentiation and is associated with the pathogenesis of multiple sclerosis by targeting MAF. The FASEB Journal. 2017; 31(2): 519-25.

77.Zhou Y,ZhangX,KlibanskiA.MEG3 noncodingRNA: atumorsuppressor.JMolEndocrinol.2012;48(3):R45-53.

78. Ghafouri-Fard S, Taheri M. maternally expressed gene 3 (MEG3): A tumor suppressor long non coding RNA. Biomed Pharmacother. 2019; 118: 109-29.

79. Li J-Q, Hu S-Y, Wang Z-Y, Lin J, Jian S, Dong Y-C, et al. Long non-coding RNA MEG3 inhibits microRNA-125a-5p expression and induces immune imbalance of Treg/Th17 in immune thrombocytopenic purpura. Biomedicine \& pharmacotherapy. 2016; 83: 905-11.

80. Moradi A, Naiini MR, Yazdanpanahi N, Tabatabaeian H, Nabatchian F, Baghi M, et al. Evaluation of The Expression Levels of Three Long Non-Coding RNAs in Multiple Sclerosis. Cell Journal (Yakhteh). 2020; 22(2): 165.

81. Rivandi M, Pasdar A, Hamzezadeh L, Tajbakhsh A, Seifi S, Moetamani-Ahmadi M, et al. The prognostic and therapeutic values of long noncoding RNA PANDAR in colorectal cancer. J Cell Physiol. 2019; 234(2): 1230-6. 


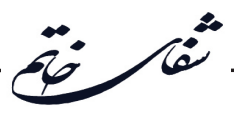

82. Kim C, Kang D, Lee EK, Lee J-S. Long noncoding RNAs and RNA-binding proteins in oxidative stress, cellular senescence, and age-related diseases. Oxidative Medicine and Cellular Longevity. 2017; 21.

83. Ivanov S, Merlin J, Lee MKS, Murphy AJ, Guinamard RR. Biology and function of adipose tissue macrophages, dendritic cells and B cells. Atherosclerosis. 2018; 271: 102-10.

84. Wang $\mathrm{P}$, Xue $\mathrm{Y}$, Han $\mathrm{Y}$, Lin $\mathrm{L}, \mathrm{Wu} \mathrm{C}, \mathrm{Xu}$ $\mathrm{S}$, et al. The STAT3-binding long noncoding RNA lnc-DC controls human dendritic cell differentiation. Science. 2014; 344(6181): 310-13.

85. Liu AY, Torchia BS, Migeon BR, Siliciano RF. The Human NTT Gene: Identification of a Novel 17-kb Noncoding Nuclear RNA Expressed in Activated CD4 ${ }^{+}$T Cells. Genomics. 1997; 39(2): 171-84.

86. Lotfi R, Yari K. The Role of Semaphorins and their Receptors in the Immune System and their Relation to Multiple Sclerosis. The Neuroscience Journal of Shefaye Khatam. 2018; 6(4): 75-92.

87. Sung T-L, Rice AP. Effects of prostratin on Cyclin T1/
$\mathrm{P}-\mathrm{TEFb}$ function and the gene expression profile in primary resting $\mathrm{CD}^{+} \mathrm{T}$ cells. Retrovirology. 2006; 3(1): 1-14.

88. Eftekharian MM, Ghafouri-Fard S, Soudyab M, Omrani MD, Rahimi M, Sayad A, et al. Expression analysis of long non-coding RNAs in the blood of multiple sclerosis patients. Journal of Molecular Neuroscience. 2017; 63(3): 333-41.

89. Patoughi M, Ghafouri-Fard S, Arsang-Jang S, Taheri M. GAS8 and its naturally occurring antisense RNA as biomarkers in multiple sclerosis. Immunobiology. 2019; 224(4): 560-4.

90. Gharesouran J, Taheri M, Sayad A, Mazdeh M, Omrani MD. Integrative analysis of OIP5AS1/HUR1 to discover new potential biomarkers and therapeutic targets in multiple sclerosis. Journal of cellular physiology. 2019; 234(10): 17351-60.

91. Ghoveud E, Teimuri S, Vatandoost J, Hosseini A, Ghaedi K, Etemadifar M, et al. Potential biomarker and therapeutic LncRNAs in multiple sclerosis through targeting memory B cells. Neuromolecular medicine. 2020; 22(1): 111-20. 